\title{
Effects of temperature on energetics and the growth pattern of benthic octopuses
}

\author{
Jessica André ${ }^{1, *}$, Eric P. M. Grist ${ }^{2}$, Jayson M. Semmens ${ }^{1}$, Gretta T. Pecl ${ }^{1}$, \\ Susumu Segawa ${ }^{3}$ \\ ${ }^{1}$ Tasmanian Aquaculture and Fisheries Institute, Marine Research Laboratories, University of Tasmania, Private Bag 49, \\ Hobart, Tasmania 7001, Australia \\ ${ }^{2}$ Environmental Research Institute, North Highland College, UHI Millenium Institute, Caithness, KW14 7JD, UK \\ ${ }^{3}$ Department of Ocean Sciences, Faculty of Marine Science, Tokyo University of Marine Science and Technology, \\ 4-5-7 Konan, Minato-ku, Tokyo 108-8477, Japan
}

\begin{abstract}
In octopus, growth trajectories have implications for survivorship, adult size and fecundity. Many species exhibit a 2-phase growth pattern starting with rapid exponential growth before shifting to a slower (commonly power) growth rate. Based on the concept that energy conservation enforces this threshold, we developed a temperature-dependent model which incorporates the energy balance between food intake and expenditure in growth and metabolism. We employed the model to investigate growth patterns occurring at different temperatures for 2 octopus species, Octopus ocellatus and O. pallidus. Model projections were consistent with laboratory data and suggest that increases in temperature as small as $1^{\circ} \mathrm{C}$ could have a significant influence on cephalopod growth, affecting the threshold body mass by up to $15.5 \%$ and the body mass at $100 \mathrm{~d}$ by up to $62.6 \%$. Sensitivity analyses suggest that threshold size is more sensitive than threshold age to any given change in parameter values, and that metabolic rate has the greatest influence on the growth threshold. This model provides a basis for predicting individual growth trajectories and consequential population structure of natural octopus populations. This type of analysis also has the potential to predict optimum conditions for a species and could be a powerful tool for predicting how climate change might affect species distribution as well as population structure and abundance.
\end{abstract}

KEY WORDS: Energy balance $\cdot 2$-phase growth $\cdot$ Gold-spot octopus $\cdot$ Pale octopus $\cdot$ Climate change

\section{INTRODUCTION}

Octopus are important ecological components of marine food webs, being simultaneously prey items, voracious predators and an increasingly important target for fisheries worldwide (Clarke 1996, Boyle \& Rodhouse 2005, FAO 2005). One of the most remarkable characteristics of octopus are their energy efficiencies, which allows them to sustain high growth rates during their short lifespans (usually < 18 mo) while maturing and reproducing. This is facilitated by a generalist diet, very high consumption rates, high conversion rates, efficient use of oxygen and their unique ability like most cephalopods to sustain continuous hyperplastic and hypertrophic muscle growth (Jackson \& O'Dor
2001, Semmens et al. 2004). However, despite recent advances in this area (Wells \& Clarke 1996, Daly \& Peck 2000, Petza et al. 2006), our understanding of the energetics of octopus growth remains sketchy. There are still debates as to the actual form of the growth curve for wild octopus, in particular whether they display a 2-phase growth pattern (an initial rapid exponential phase followed by a slower second growth phase) as is often observed in captivity (Forsythe \& Hanlon 1988, Domain et al. 2000, Semmens et al. 2004, Boyle \& Rodhouse 2005). Analyses of field data may never shed light on this issue as field size-at-age data for highly variable species such as squid typically contain few data for the early part of the life span and frequently exhibit a greater scattering of data points with 
increasing age (Arkhipkin \& Roa-Ureta 2005). This causes serious difficulties in statistical approaches that depend only on regression inference to estimate the individual growth curve, so that the curve may often be misspecified when data are inadequate to support the relationship being fitted. Grist \& Jackson (2004) introduced the concept of energy balance as a mechanism that might lead to 2-phase growth in cephalopods. The authors hypothesised that after reaching a critical size, the energy intake from food would no longer sustain the energetic demands of both metabolism and individual growth at the current level. As a consequence, individuals are predicted to shift to a slower growth rate, thus resulting in a 2-phase growth pattern. While taking account of body size, this model does not explicitly invoke environmental temperature, which is the most important abiotic factor influencing cephalopod life history alongside nutrition. Since temperature influences all aspects of the energy budget and, according to the hypothesis of Grist \& Jackson (2004), energetics determines the transition between the 2 growth phases, temperature must therefore influence the transition body mass and transition age out of exponential growth, and consequently individual growth trajectories. This has implications for survivorship (Calow 1987), adult size (Forsythe \& Van Heukelem 1987) and hence fecundity (Mangold 1987) at the individual level, subsequently influencing population structure. Assessing the effect of temperature on the growth of octopus is therefore crucial to understanding the population dynamics of these short-lived and increasingly exploited species, particularly in the light of predicted warming of the oceans. Our main aim is to investigate the influence of temperature on the energetics of octopus, and its associated impact on growth, through the utilisation of a temperaturedependent energy balance model.

\section{THE ENERGY BALANCE MODEL}

\section{Concept}

The traditional formulation of the energy budget of marine animals is based on the balanced energy equation formulated by Winberg (1956), which follows the fundamental law of energy conservation

$$
F_{\mathrm{T}}=M+G+W
$$

where $F_{\mathrm{T}}$ is the total energy intake rate from food, $M$ and $G$ are the respective rates at which energy is expended in metabolism and growth (both somatic and reproductive), and $W$ is the rate at which energy is wasted in excretions such as urine, faeces and other wastage (e.g. mucus, shed sucker cuticles). In this paper, these rates are expressed in $\mathrm{kJ} \mathrm{d}^{-1}$. Unlike somatic growth, reproductive growth in octopus differs between sexes in both energy allocation and timing. Males appear to mature earlier, coinciding with the shift between growth phases, whereas females tend to mature in the second slower phase of growth (Semmens et al. 2004). Assessing reproductive investment has been achieved for a few species (Boyle \& Knobloch 1984, Perez \& Haimovici 1991, Cortez et al. 1995) but estimating the onset of sexual maturation remains problematic, as the influence of food availability and temperature on this aspect of reproduction has yet to be quantified. Given the deficiency in information, we did not incorporate reproductive growth to avoid introducing unsupportable complexity into the model. The current representation is consequently characteristic of females' energetics.

The rate $W$ can be eliminated by way of an assimilation efficiency parameter $A$, defined as the proportion of the intake energy which is not lost in excreta (Kleiber 1947), so that

$$
F_{\mathrm{T}} \times A=F=M+G
$$

In order for an individual to survive there must be sufficient energy available to support metabolism and growth so that $F \geq M+G$ or equivalently $F-M-G \geq 0$, which hence gives rise to an energy balance constraint (Grist \& Jackson 2004).

The dependencies of metabolic rate $M$ and food intake rate $F$ on body mass $B$ (in $g$ ) have previously been characterised by an allometric scaling law of the form $y=q B^{p}$ where $p>0$ is a scaling exponent and $q>0$ is a constant (West et al. 1997, Boyle \& Rodhouse 2005, O'Dor et al. 2005). The growth rate $G$ during the exponential phase is (by definition) directly proportional to body mass. Hence, the required supply of energy $E(B)$ can be expressed as a function of body mass $B$

$$
\begin{aligned}
E(B) & =F(B)-M(B)-G(B) \\
& =q_{1} B^{p_{1}}-q_{2} B^{p_{2}}-q_{3} B
\end{aligned}
$$

where $E(B)$ must remain positive in order for an individual to survive (Fig. 1).

Beyond a critical body weight $B^{*}$ achieved at age $t^{*}$ (where $B^{*}=B_{0} \exp \left(m t^{*}\right.$ ) and $B_{0}$ is the hatch size) when $E(B)=0$, it follows that an individual would be unable to support its total energy expenditure. Grist \& Jackson (2004) hypothesised that a shift from exponential growth would then be necessary.

The value of 0.75 has been traditionally assigned as the scaling exponent of metabolism $p_{2}$ for many animals (Kleiber 1932); however, octopus generally have higher $p_{2}$ values which may reach up to 0.90 (Katsanevakis et al. 2005). The $q_{i}$ are generally speciesspecific (West et al. 1997) and are typically estimated from experimental studies. 


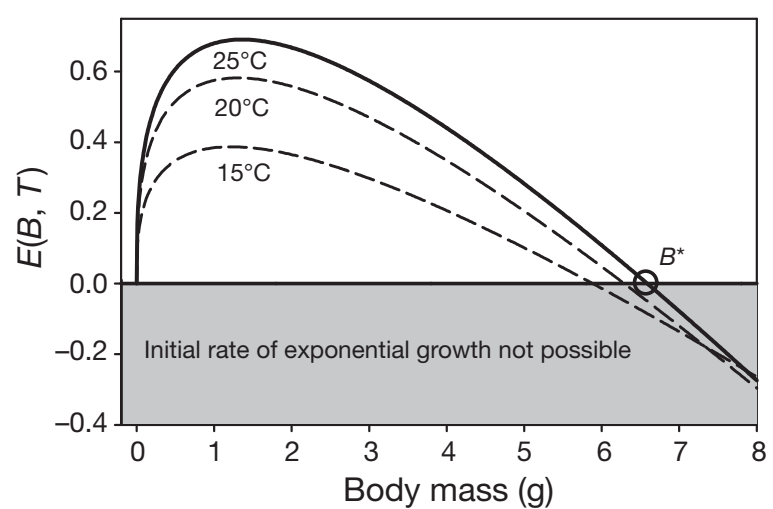

Fig. 1. Octopus ocellatus. Energy balance function $E(B, T)$ when parameterised for individuals reared at 15,20 and $25^{\circ} \mathrm{C}$ with data obtained from Expt 1 . By definition, threshold body mass $B^{*}$ is reached when $E(B, T)=0$

\section{Incorporation of temperature dependence}

Since temperature $T$ affects feeding, metabolic and growth rates in cephalopods, we incorporate temperature dependency by modifying $E(B)$ to $E(B, T)$ and through specifying $q_{i}$ as temperature dependent $q_{i}(T)$ so that

$$
\begin{aligned}
E(B, T) & =F(B, T)-M(B, T)-G(B, T) \\
& =q_{1}(T) B^{p_{1}}-q_{2}(T) B^{p_{2}}-q_{3}(T) B
\end{aligned}
$$

where the functions $q_{i}(T)$ were empirically determined from temperature-dependent data sets. We assume all body mass exponents $p_{i}$ to be species-specific and independent of temperature as noted with $p_{2}$ by Zeuthen (1953), von Bertalanffy (1957) and Katsanevakis et al. (2005).

\section{METHODS}

We parameterised the model for 2 commercially exploited octopus, Octopus ocellatus and O. pallidus. Model parameters for each species were estimated from data published in the literature and collected in laboratory experiments, henceforth referred to as Expts 1, 2 and 3. Parameter values for both species are summarised in Table 1.

Data sets. Expt 1 provided data on the growth and feeding rates and oxygen consumption of Octopus ocellatus, details of which are published in Segawa \& Nomoto (2002). Eleven juveniles hatched in captivity were reared for $205 \mathrm{~d}$ at $20 \pm 1^{\circ} \mathrm{C}(\mathrm{n}=6)$ and $25 \pm 1^{\circ} \mathrm{C}$ $(\mathrm{n}=5)$. Individuals were fed hermit crabs Clibanarius

Table 1. Octopus ocellatus and O. pallidus. Parameter values for the temperature-dependent energy balance model. B: body

\begin{tabular}{|c|c|c|c|c|}
\hline Eq. & Parameter & $\begin{array}{l}\text { Value for } \\
\text { O. pallidus }\end{array}$ & $\begin{array}{l}\text { Value for } \\
\text { O. ocellatus }\end{array}$ & Source \\
\hline \multirow[t]{6}{*}{ (9) } & \multicolumn{4}{|l|}{ Growth rate: $k_{3}\left[m_{\mathrm{opt}}-d \times\left(T_{\mathrm{opt}}-T\right)^{2}\right] B$} \\
\hline & \multirow{2}{*}{$\begin{array}{l}\text { Optimum temperature for growth }\left(T_{\text {opt }}\right)\left({ }^{\circ} \mathrm{C}\right) \\
\text { Growth rate at } T_{\text {opt }}\left(m_{\text {opt }}\right)\left(\mathrm{g} \mathrm{d}^{-1}\right)\end{array}$} & 16.5 & 25 & Present study ${ }^{a}$, Segawa \& Nomoto $(2002)^{b}$ \\
\hline & & 0.0167 & 0.0750 & Present study $\mathrm{a}^{\mathrm{a}, \mathrm{b}}$ \\
\hline & \multirow[t]{3}{*}{ Parabolic constant $(d)$ if $\quad T \leq T_{\text {opt }}$} & 0.00039 & 0.00026 & Present study ${ }^{\mathrm{a}, \mathrm{b}}$ \\
\hline & & 0.00039 & 0.0015 & Present study ${ }^{\mathrm{a}, \mathrm{b}}$ \\
\hline & & 4.05848 & 4.05848 & O'Dor \& Wells $(1987)^{\mathrm{a}, \mathrm{b}}$ \\
\hline \multirow[t]{9}{*}{$(11)$} & \multicolumn{4}{|l|}{ Feeding rate: $\left[f_{\mathrm{opt}}-d_{f} \times\left(T_{f \mathrm{opt}}-T\right)^{2}\right] B^{p 1}$} \\
\hline & Assimilation efficiency $(A)$ & $90 \%$ & $90 \%$ & Wells et al. $(1983)^{\mathrm{a}, \mathrm{b}}$ \\
\hline & Energy equivalent of food $\left(k_{f}\right)\left(\mathrm{kJ} \mathrm{g} \mathrm{dry} \mathrm{wt}^{-1}\right)$ & 6.82353 & 11.05 & Perez et al. $(2006)^{a}$, McKinney et al. $(2004)^{b}$ \\
\hline & Conversion coefficient wet wt to dry wt $\left(k_{\mathrm{w} / \mathrm{d}}\right)$ & 0.249 & 0.339 & Present study ${ }^{\mathrm{a}}$ McKinney et al. $(2004)^{\mathrm{b}}$ \\
\hline & Optimum temperature for feeding $\left(T_{f o p t}\right)\left({ }^{\circ} \mathrm{C}\right)$ & 18.4 & 28.6 & Present study $\mathrm{a}, \mathrm{b}$ \\
\hline & Feeding rate at $T_{\text {fopt }}\left(f_{\text {opt }}\right)\left(\mathrm{kJ} \mathrm{d}^{-1}\right)$ & 0.584 & 1.064 & Present study ${ }^{\mathrm{a}, \mathrm{b}}$ \\
\hline & \multirow[t]{2}{*}{ Parabolic constant $\left(d_{f}\right)$ if $\quad T \leq$} & 0.0083 & 0.0025 & Present study ${ }^{a, b}$ \\
\hline & & 0.0276 & 0.0920 & Present study ${ }^{\mathrm{a}, \mathrm{b}}$ \\
\hline & Feeding rate exponent $\left(p_{1}\right)$ & 1.17 & 0.39 & Present study ${ }^{\mathrm{a}, \mathrm{b}}$ \\
\hline \multirow[t]{6}{*}{ (12) } & \multicolumn{4}{|l|}{ Metabolic rate: $k_{1} \exp \left(a_{2}+\frac{b_{2}}{T}\right) B^{p_{2}}$} \\
\hline & Metabolic rate exponent $\left(p_{2}\right)$ & 0.88 & 0.81 & Present study ${ }^{\mathrm{a}}$, Segawa \& Nomoto $(2002)^{\mathrm{b}}$ \\
\hline & \multirow{2}{*}{ Conversion factor $\mathrm{O}_{2} \mathrm{mg} \mathrm{h}^{-1}$ to $\mathrm{kJ} \mathrm{d}^{-1}\left(k_{1}\right)$} & 0.33758 & 0.33758 & Prosser $(1973)^{a, b}$, Elliott \& Davison $(1975)^{a, b}$ \\
\hline & & 273.15 & 273.15 & \\
\hline & Constant $\left(a_{2}\right)$ & 21.80 & 21.80 & Katsanevakis et al. $(2005)^{a, b}$ \\
\hline & Constant $\left(b_{2}\right)$ & -6952.8 & -6952.8 & Katsanevakis et al. $(2005)^{\mathrm{a}, \mathrm{b}}$ \\
\hline
\end{tabular}
weight $(\mathrm{g}), \mathrm{T}$ : temperature $\left({ }^{\circ} \mathrm{C}\right)$ 
virescens and Pagurus spp. ad libitum. Individual food consumption was measured daily and octopus were weighed every 6 to $14 \mathrm{~d}$ to assess growth. The oxygen consumption curves provided the species-specific metabolic exponent $p_{2}$, which was calculated as the mean $p_{2}$ value obtained under the 2 temperature treatments. One individual in the $20^{\circ} \mathrm{C}$ treatment died at age $63 \mathrm{~d}$ and was excluded from the present analyses because there were too few data points to establish valid feeding and growth curves.

Expt 2 provided data on the growth rates and feeding rates of Octopus pallidus, details of which are published in André et al. (2008). Eight juveniles hatched in captivity were reared for $143 \mathrm{~d}$ at $14.7 \pm 0.08^{\circ} \mathrm{C}( \pm \mathrm{SE})$ $(\mathrm{n}=4)$ and $16.9 \pm 0.12^{\circ} \mathrm{C}(\mathrm{n}=4)$. Animals were fed 2 porcelain crabs Petrolisthes elongatus daily, totalling between 4 and $12 \%$ of the octopus body weight $\mathrm{d}^{-1}$. The level of food offered was comparable with the level of food consumed by other octopus species reared in captivity under ad libitum conditions (Joll 1977, Mangold 1983, O'Dor \& Wells 1987) and the survival rate over the duration of the experiment was $75 \%$ (with 2 individuals dying before the end of the experiment in the warm treatment). Individual food consumption was measured daily and octopus were weighed every 5 to $10 \mathrm{~d}$ to assess growth. One individual in the $16.9^{\circ} \mathrm{C}$ treatment was excluded from the analyses as it died at age $57 \mathrm{~d}$ and there were too few data points to establish valid feeding and growth curves.

Expt 3 provided data on the metabolism of Octopus pallidus. Oxygen consumption at $18^{\circ} \mathrm{C}$ was measured at ages 93, 132 and $146 \mathrm{~d}$ for 2 randomly selected individuals from Expt 2 . The resulting curve provided the species-specific metabolic exponent $p_{2}$. Further details of the experimental procedures are presented in Appendix 1.

Experimental estimation of transition body mass and age. We used the method of Hatfield et al. (2001) based on instantaneous relative growth rate (IRGR) to identify the transition point between the growth phases. If growth is exponential, IRGR (i.e. \% increase in body mass $\mathrm{d}^{-1}$ ) will remain constant from measurement to measurement, although there will be some fluctuation as in any biological system (Hatfield et al. 2001). The point at which IRGR starts to decline steadily marks the end of the initial exponential growth phase. The instantaneous growth rate for cephalopods following exponential growth is typically calculated according to the equation:

$$
\text { IRGR }=\left(\frac{\ln B_{2}-\ln B_{1}}{t_{2}-t_{1}}\right) \times 100
$$

where $B_{2}$ is the body mass at time $t_{2}$ and $B_{1}$ is the body mass at time $t_{1}$ (Forsythe \& Van Heukelem 1987).
Using this method, we clearly identified a 2-phase growth pattern for Octopus ocellatus individuals in Expt 1 (Fig. 2) with a mean $\pm 95 \%$ CI threshold age $t^{*}$ of $43 \pm 27 \mathrm{~d}$ at $20^{\circ} \mathrm{C}$ (range $=15$ to $71 \mathrm{~d}, \mathrm{n}=5$ ) and $37 \pm 12 \mathrm{~d}$ at $25^{\circ} \mathrm{C}$ (range $=25$ to $49 \mathrm{~d}, \mathrm{n}=5$ ), and a mean $\pm 95 \%$ CI threshold body mass $B^{*}$ of $2.5 \pm 3.5 \mathrm{~g}$ at $20^{\circ} \mathrm{C}$ (range $=0$ to $6.0 \mathrm{~g}, \mathrm{n}=5$ ) and $2.3 \pm 1.6 \mathrm{~g}$ at $25^{\circ} \mathrm{C}$ (range $=0.7$ to $3.9 \mathrm{~g}, \mathrm{n}=5$ ). No threshold was detected for $O$. pallidus in Expt 2 as growth remained exponential during the duration of the experiment (Fig. 2).

Model parameterisation. Growth rate: Growth studies have long established that temperature strongly influences the growth rate of cephalopods (e.g. Mangold \& von Boletzky 1973, Forsythe \& Hanlon 1988, Leporati et al. 2007, André et al. 2008). The dependence of growth rate on temperature in fish has been modelled with an inverted parabola to represent the general nonlinear decrease in growth rate observed towards extreme temperatures (e.g. Ricker 1979, Bartsch 2002). This model has a central optimum, corresponding to the maximum growth rate, and a symmetrical drop-off on both sides. Based on this inverted parabolic function, the temperature mediation of growth rate coefficient $m$ is given by:

$$
m(T)=m_{\mathrm{opt}}-d\left(T_{\mathrm{opt}}-T\right)^{2}
$$

where $m_{\text {opt }}$ is the maximum value of $m(T)$ at the optimum temperature, $d$ is a constant, $T_{\text {opt }}$ is the optimum temperature for maximum growth and $T$ is the ambient temperature. However, $T_{\text {opt }}$ may not necessarily be the midpoint of the species' temperature range so that asymmetric curves might follow from introducing temperature limits on either side of the optimum (Bartsch 2002). The temperature-dependence of growth rate is then expressed by 2 equations:

$$
\begin{aligned}
m(T) & =m_{\mathrm{opt}}-d_{1}\left(T_{\mathrm{opt}}-T\right)^{2} & & T<T_{\mathrm{opt}} \\
& =m_{\mathrm{opt}}-d_{2}\left(T_{\mathrm{opt}}-T\right)^{2} & & T>T_{\mathrm{opt}}
\end{aligned}
$$

During exponential growth at constant temperature, instantaneous growth rate (in $\mathrm{g} \mathrm{d}^{-1}$ ) is given by

$$
G(B)=\frac{\mathrm{d} B}{\mathrm{~d} t}=m B_{0} \exp (m t)=m B
$$

This can be expressed in terms of its energy equivalent (in $\mathrm{kJ} \mathrm{d}^{-1}$ ) as a function of body mass with temperature dependence incorporated from Eq. (6) to obtain

$$
G(B, T)=q_{3}(T) B=k_{3} m(T) B=k_{3}\left[m_{\mathrm{opt}}-d\left(T_{\mathrm{opt}}-T\right)^{2}\right] B
$$

where $k_{3}$ is the $\mathrm{kJ}$ energy equivalent of $1 \mathrm{~g}$ of octopus tissue.

To estimate early post-hatch growth rate $m$ at different environmental temperatures, we performed, for 
each temperature treatment (warm or cool) and each species, a regression of body mass versus time using nonlinear mixed-effect models with an exponential model $B=B_{0} \exp (m t)$ (Fig. 2, Table 2). This standard approach for repeated measures uses maximum likelihood estimation with an underlying assumption that individual data are normally distributed to determine parameter estimates (Lindstrom \& Bates 1990).

For Octopus ocellatus, the regression was only performed up to the mean threshold point, after which octopus entered a slower growth phase. We assumed the growth rate $m$ to be 0 at the lower and upper limit of a species' thermal range, namely 10 and $23^{\circ} \mathrm{C}$ for $O$. pallidus, and 8 and $32^{\circ} \mathrm{C}$ for $O$. ocellatus. For O. pal- lidus, we obtained the parameters $m_{\mathrm{opt}}, T_{\mathrm{opt}}$ and $d$ by nonlinear regression of an inverted parabolic curve (Eq. 6) to the combined data sets of 'growth rate versus temperature' data pairs from Expt 2 and the 2 'zero growth rate versus temperature' data pairs estimated from the thermal range.

For Octopus ocellatus, we estimated $m_{\text {opt }}$ to be the maximum growth rate observed in Expt $1\left(0.075 \mathrm{~g} \mathrm{~d}^{-1}\right.$ with corresponding $T_{\text {opt }}$ of $25^{\circ} \mathrm{C}$ ), which resulted in an asymmetrical inverted parabolic curve for temperature-dependence (Eq. 7). Parameter $d_{1}$ was obtained from nonlinear regression of an inverted parabolic curve to the point pair $\left(m_{\mathrm{opt}}, T_{\mathrm{opt}}\right)$ and the 'zero growth rate versus temperature' data pairs $(0,8)$ and $(0,42)$.
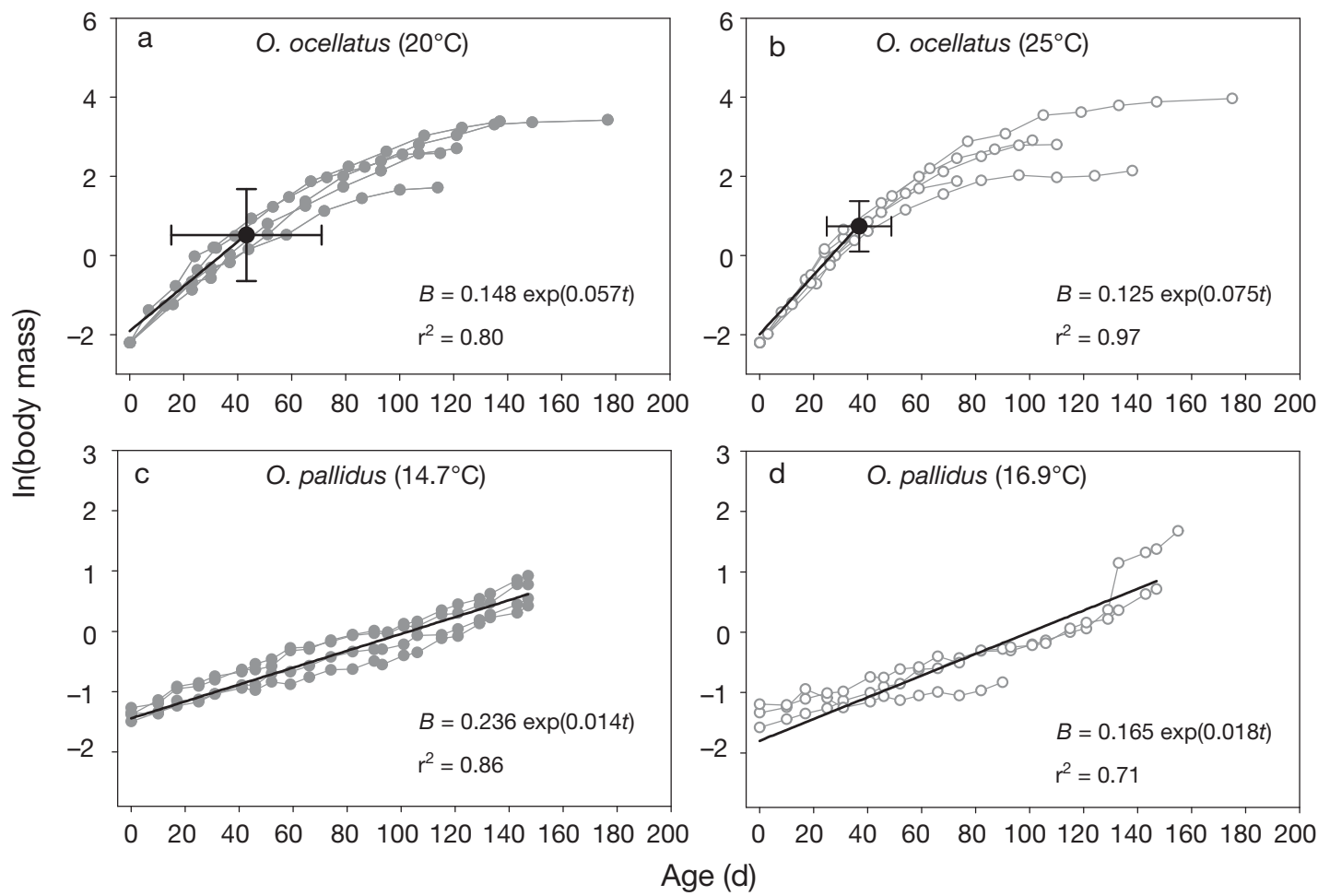

Fig. 2. Octopus ocellatus and O. pallidus. Individual growth curves for O. ocellatus at (a) $20^{\circ} \mathrm{C}(\mathrm{n}=5)$ and (b) $25^{\circ} \mathrm{C}(\mathrm{n}=5$ ), and $O$. pallidus at (c) $14.7^{\circ} \mathrm{C}(\mathrm{n}=4)$ and $(\mathrm{d}) 16.9^{\circ} \mathrm{C}(\mathrm{n}=3)$. The solid black lines, estimated from nonlinear mixed-effect models, represent the mean growth curve for the initial growth phase and the black dots represent the mean transition age and body mass

$( \pm 95 \% \mathrm{CI})$ out of the exponential growth phase

Table 2. Octopus ocellatus and O. pallidus. Feeding rate and growth parameters with associated SE estimated by nonlinear mixed-effect models

\begin{tabular}{|c|c|c|c|c|c|}
\hline \multirow[t]{2}{*}{ Species } & \multirow{2}{*}{$\begin{array}{c}\text { Temperature } \\
\left({ }^{\circ} \mathrm{C}\right)\end{array}$} & \multicolumn{2}{|c|}{ Feeding rate: $F=q_{1} B^{p_{1}}$} & \multicolumn{2}{|c|}{ Growth: $B=B_{0} \exp (m t)$} \\
\hline & & $q_{1} \pm \mathrm{SE}$ & $p_{1} \pm \mathrm{SE}$ & $B_{0} \pm \mathrm{SE}$ & $m \pm \mathrm{SE}$ \\
\hline \multirow[t]{2}{*}{ O. ocellatus } & 20.0 & $0.778 \pm 0.0402$ & $0.46 \pm 0.0223$ & $0.148 \pm 0.0192$ & $0.057 \pm 0.0047$ \\
\hline & 25.0 & $1.117 \pm 0.1316$ & $0.31 \pm 0.0444$ & $0.125 \pm 0.0128$ & $0.075 \pm 0.0039$ \\
\hline \multirow[t]{2}{*}{ O. pallidus } & 14.7 & $0.464 \pm 0.0300$ & $1.206 \pm 0.1453$ & $0.236 \pm 0.0237$ & $0.014 \pm 0.0003$ \\
\hline & 16.9 & $0.517 \pm 0.0451$ & $1.126 \pm 0.0912$ & $0.165 \pm 0.0648$ & $0.018 \pm 0.0073$ \\
\hline
\end{tabular}


Parameter $d_{2}$ was obtained from nonlinear regression of an inverted parabolic curve to the point pair $\left(m_{\mathrm{opt}}\right.$, $T_{\mathrm{opt}}$ ) and the 'zero growth rate versus temperature' data pairs $(0,18)$ and $(0,32)$. We assumed coefficient $k_{3}$ for both species to be the same as for $O$. cyanea, which we sourced from O'Dor \& Wells (1987).

A plot of the temperature-dependence of growth rate for both species is represented in Fig. 3.

Feeding rate: From Expts 1 and 2, we estimated individual feeding rate $F$ (in $\mathrm{kJ} \mathrm{d}^{-1}$ ) every 5 to $14 \mathrm{~d}$ over the duration of the experiments using the formula:

$$
F=F_{\mathrm{w}} A k_{\mathrm{f}} k_{\mathrm{w} / \mathrm{d}}
$$

where $F_{\mathrm{w}}$ is the feeding rate in $\mathrm{g}$ wet wt $\mathrm{d}^{-1}, A$ is the assimilation efficiency, $k_{\mathrm{f}}$ is the energy equivalent of the prey tissue in $\mathrm{kJ} \mathrm{g}^{-1}$ dry wt and $k_{\mathrm{w} / \mathrm{d}}$ is the wet weight to dry weight conversion coefficient for prey tissue. For both octopus species, we used the general cephalopod $A=90 \%$ from Wells et al. (1983). The $k_{\mathrm{f}}$ for porcelain crabs was sourced from Perez et al. (2006) and we estimated $k_{\mathrm{w} / \mathrm{d}}$ from the wet:dry weight

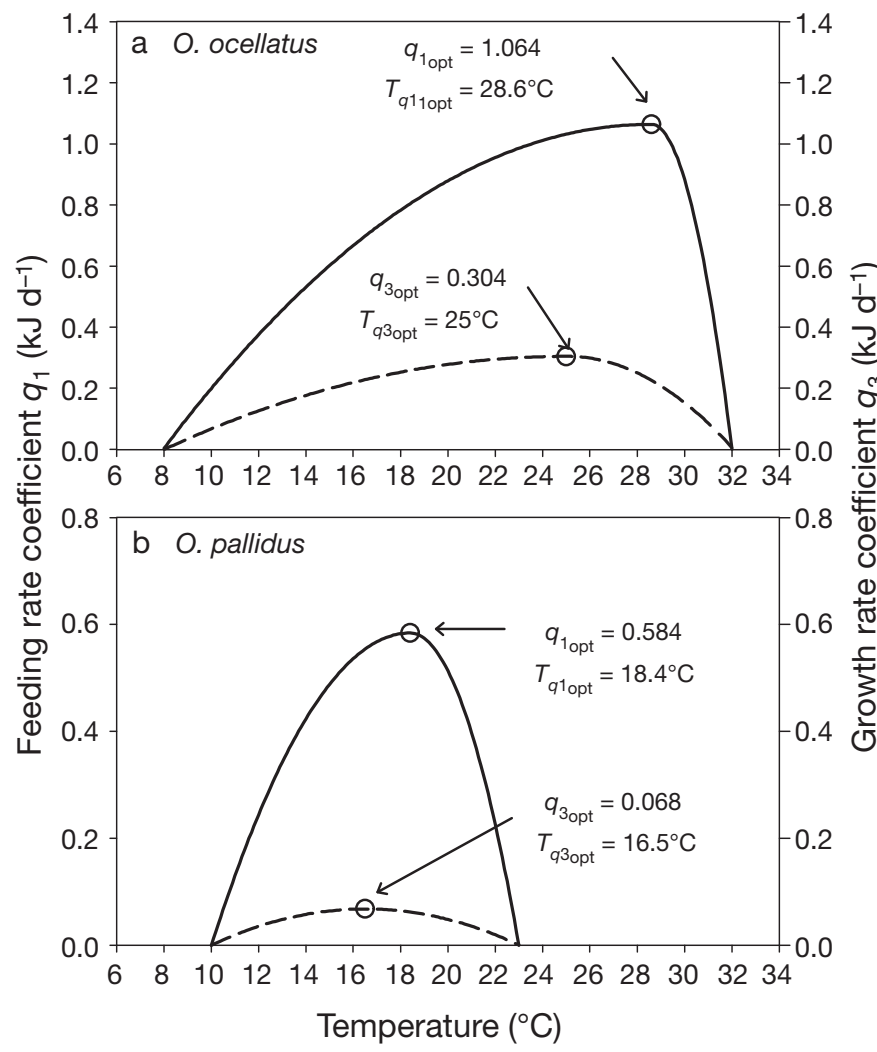

Fig. 3. (a) Octopus ocellatus and (b) O. pallidus. Feeding rate coefficient $q_{1}$ (solid line) and the growth rate coefficient $q_{3}$ (dashed line) as a function of temperature $T$. For each species, symmetric or asymmetric inverted parabolic curves were used to describe $q_{1}(T)$ and $q_{3}(T)$ across the thermal range encountered in nature ratio of 30 crab samples from Expt 2. We used the values of $k_{\mathrm{f}}$ and $k_{\mathrm{w} / \mathrm{d}}$ estimated by McKinney et al.(2004) for the hermit crab Pagurus longicarpus in lieu of the other hermit crab species (Pagurus spp. and Clibanarius virescens). We performed regressions of feeding rate versus body mass using a nonlinear mixedeffect model with a power model $F(B)=q_{1} B^{p_{1}}$ for each species and temperature treatment (warm or cool) (Fig. 4, Table 2).

Higher temperatures result in higher feeding rates in octopus (Mangold \& von Boletzky 1973, Van Heukelem 1973, Mangold 1983, Segawa \& Nomoto 2002, André et al. 2008). Towards the maximal thermal tolerance of a species, however, the feeding rate starts to decline (Mangold 1983). We therefore assumed the relationship between $q_{1}$ and temperature to be an asymmetrical inverted parabola as for growth rate so that:

$$
F(B, T)=q_{1}(T) B^{p_{1}}
$$

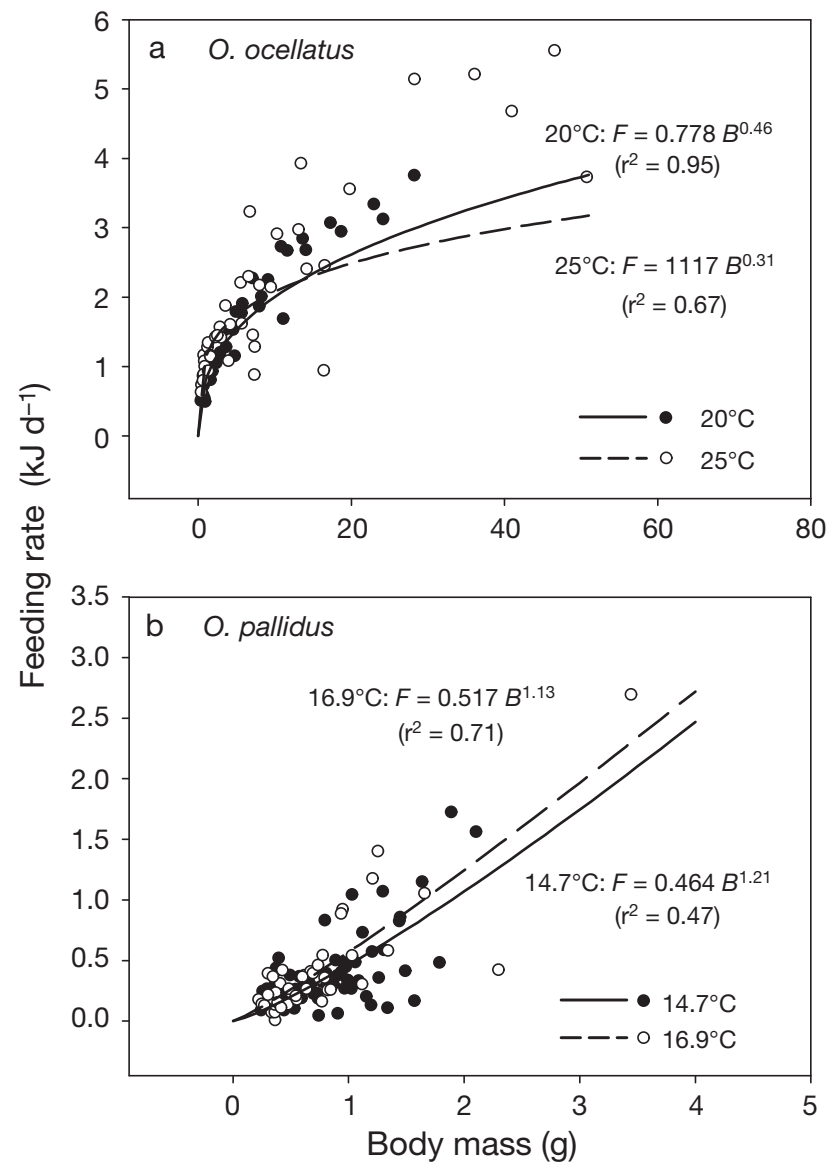

Fig. 4. Octopus ocellatus and $O$. pallidus. Feeding rate $F$ as a function of body mass $B$ estimated from nonlinear mixedeffect models for (a) O. ocellatus at $20^{\circ} \mathrm{C}$ (solid line, $\mathrm{n}=5$ ) and $25^{\circ} \mathrm{C}$ (dashed line, $\mathrm{n}=5$ ) and (b) O. pallidus at $14.7^{\circ} \mathrm{C}$ (solid line, $\mathrm{n}=4$ ) and $16.9^{\circ} \mathrm{C}$ (dashed line, $\mathrm{n}=3$ ) 
with

$$
\begin{aligned}
q_{1}(T) & =f_{\mathrm{opt}}-d_{f 1}\left(T_{f_{\mathrm{opt}}}-T\right)^{2} & & T<T_{f_{\mathrm{opt}}} \\
& =f_{\mathrm{opt}}-d_{f 2}\left(T_{f_{\mathrm{opt}}}-T\right)^{2} & & T>T_{f_{\mathrm{opt}}}
\end{aligned}
$$

where $T_{f o p t}$ is the optimum temperature for maximum feeding rate $f_{\text {opt }}, d_{f 1}$ and $d_{f 2}$ are constants and $T$ is the ambient temperature. We assumed the difference between $T_{\text {opt }}$ and $T_{\text {fopt }}$ to be relative to the species' thermal range and proportionally constant between octopus species. Based on known thermal range and $T_{\text {opt }}$ of our study species and data for Octopus vulgaris (thermal range: 12 to $29^{\circ} \mathrm{C}, T_{\text {opt }}=17.5^{\circ} \mathrm{C}, T_{\text {fopt }}=20^{\circ} \mathrm{C}$ ) from Aguado Giménez \& García García (2002), we estimated $T_{\text {fopt }}$ to be $28.6^{\circ} \mathrm{C}$ for O. ocellatus (thermal range: 8 to $32^{\circ} \mathrm{C}, T_{\text {opt }}=25^{\circ} \mathrm{C}$ ) and $18.4^{\circ} \mathrm{C}$ for $O$. pallidus (thermal range: 10 to $23^{\circ} \mathrm{C}, T_{\text {opt }}=16.5^{\circ} \mathrm{C}$ ). We performed a nonlinear regression of the inverted parabolic curve to the experimental 'feeding rate versus temperature' data pairs, setting the 'zero feeding rate' at 8 and $49.2^{\circ} \mathrm{C}$ for $\mathrm{O}$. ocellatus and 10 and $26.8^{\circ} \mathrm{C}$ for $O$. pallidus. The maximum feeding rate $f_{\text {opt }}$ and constant $d_{f 1}$ that minimised the sum of squares to the feeding rate data were retained for each species. The constant $d_{f 2}$ was then obtained from nonlinear regression of an inverted parabolic curve to the point pair ( $f_{\text {opt }}$ $\left.T_{f o p t}\right)$ and the 'zero growth rate versus temperature' data pairs $(0,25.2)$ and $(0,32)$ for $O$. ocellatus, and $(0,13.8)$ and $(0,23)$ for $O$. pallidus. A plot of the temperature-dependence of feeding rate for both species is represented in Fig. 3.

Metabolic rate: Temperature and body mass are the 2 most important factors linked to metabolic rate (Gillooly et al. 2001). Katsanevakis et al. (2005) developed a model of the form $M(B, T)=q_{2}(T) B^{p_{2}}$ to encompass the effect of both these factors on the oxygen consumption rate of Octopus vulgaris, and suggested that the term $q_{2}(T)$ could be generalised because metabolic rates of octopod species have a similar dependence on temperature. To obtain metabolic rate in $\mathrm{kJ} \mathrm{d}^{-1}$ as a function of temperature in ${ }^{\circ} \mathrm{C}$, we re-expressed the equation of Katsanevakis et al. (2005) as:

$$
M(B, T)=q_{2}(T) B^{p_{2}}=k_{1} \exp \left(a_{2}+\frac{b_{2}}{T+k_{2}}\right) B^{p_{2}}
$$

where $M$ is the oxygen consumption rate in $\mathrm{kJ} \mathrm{d}^{-1}, B$ is the body mass, $T$ is the temperature in ${ }^{\circ} \mathrm{C}_{1} k_{1}$ is the conversion factor from $\mathrm{mg} \mathrm{h}^{-1}$ to $\mathrm{kJ} \mathrm{d}^{-1}, k_{2}, a_{2}$ and $b_{2}$ are constants and $p_{2}$ is a species-specific metabolic rate exponent. Parameter values for $a_{2}$ and $b_{2}$ were imported from Katsanevakis et al. (2005). We estimated $p_{2}$ from Expt 1 for $O$. ocellatus and Expt 3 for $O$. pallidus. Coefficients $k_{1}$ and $k_{2}$ were obtained from the literature (Prosser 1973, Elliott \& Davison 1975). Since the original formula was tested in the temperature range 13 to $28^{\circ} \mathrm{C}$ (Kat- sanevakis et al. 2005), we determined the function $q_{2}(T)$ across the temperature ranges 13 to $28^{\circ} \mathrm{C}$ for $O$. ocellatus and 13 to $23^{\circ} \mathrm{C}$ for $O$. pallidus to avoid extrapolation.

Model estimation of transition body mass and age. We compared the threshold body mass $B^{*}$ and age $t^{*}$ estimated experimentally with model growth projections for $B^{*}$ and $t^{*}$ at the experimental rearing temperatures of 20 and $25^{\circ} \mathrm{C}$ for Octopus ocellatus and 14.7 and $16.9^{\circ} \mathrm{C}$ for $O$. pallidus.

The relationship between growth pattern and temperature was explored by plotting $B^{*}$ and $t^{*}$ as functions of temperature between the ranges of 13 and $23^{\circ} \mathrm{C}$ for Octopus pallidus and 13 and $28^{\circ} \mathrm{C}$ for O. ocellatus. Additionally, we projected growth trajectories over $100 \mathrm{~d}$ with individuals starting from the same hatch size $B_{0}$, but experiencing different temperature scenarios. We estimated growth trajectories every degree between 13 and $28^{\circ} \mathrm{C}$ for $O$. ocellatus and 13 and $23^{\circ} \mathrm{C}$ for O. pallidus. In this simple simulation, growth was assumed to be exponential in form until the transition point. The second slower growth phase was represented as linear and tangential to transition point $\left(t^{*}\right.$, $\left.B^{*}\right)$. Hatch size $B_{0}$ was representative of the species and was set to $0.11 \mathrm{~g}$ for $O$. ocellatus (Segawa \& Nomoto 2002) and $0.25 \mathrm{~g}$ for O. pallidus (Leporati et al. 2007).

Sensitivity analysis. A sensitivity analysis was performed to assess the response of model growth projections to small changes in parameter values. We used the metric of 'elasticity', in which the effect of proportional (rather than absolute) perturbations on a given output quantity are evaluated (Caswell 2001). Elasticity is defined as:

$$
S_{P}=\frac{x_{P}-x_{0}}{x_{0}} \times 100
$$

where $S_{P}(\%)$ is the elasticity of the output quantity to a given \% increase in parameter $P, x_{0}$ is the output of the original model and $x_{P}$ is the output of the model modified for parameter $P$ (Barbeau \& Caswell 1999, Lauzon-Guay et al. 2006). Elasticities of $B^{*}$ (critical transition weight) and $t^{*}$ (critical transition age) to independent perturbations of $d_{f}, T_{\text {fopt }}, f_{\text {opt }}, p_{1}, a_{2}, b_{2}, p_{2}, d, T_{\text {opt }}$ and $m_{\text {opt }}$ were calculated at 2 levels of parameter change, namely at 1 and $5 \%$. To assess the influence of temperature, the analyses were repeated at 4 temperatures across the species thermal range, namely at $15,20,25$ and $28^{\circ} \mathrm{C}$ for $\mathrm{OC}^{-}$ topus ocellatus, and at $13,16,18$ and $21^{\circ} \mathrm{C}$ for O. pallidus.

\section{RESULTS}

\section{Estimation of transition body mass and age}

For both species, there was good agreement between the laboratory observations and the projec- 
tions of the model (Table 3). Model estimates for $B^{*}$ and $t^{*}$ for Octopus ocellatus were close to the observed values (Table 3), encompassed within the 95\% $\mathrm{CI}$ at $20^{\circ} \mathrm{C}$ and just outside the $95 \% \mathrm{CI}$ at $25^{\circ} \mathrm{C}$. O. pallidus did not display a 2-phase growth pattern during the $143 \mathrm{~d}$ of the experiment and the model predicted that exponential growth would always be supported at the temperatures tested (Table 3). Hence, only results for $O$. ocellatus are presented for the remaining analyses.

\section{Impact of temperature on growth pattern}

The relationships between temperature and threshold size and between temperature and threshold age were not linear. As temperature increases, $B^{*}$ is projected to slowly increase while $t^{*}$ is projected to decrease, so that the transition out of exponential growth would occur at an earlier age but similar body mass (Fig. 5). Beyond $25^{\circ} \mathrm{C}$, however, $B^{*}$ and $t^{*}$ are both projected to increase so that the transition from exponential growth would be expected to occur later and at higher body mass.

Projected growth trajectories suggested that higher temperatures do not necessarily translate to higher body mass, with individuals growing at $23^{\circ} \mathrm{C}$ reaching higher body mass at $100 \mathrm{~d}$ than those at $28^{\circ} \mathrm{C}$ (Fig. 6). Projections at temperatures between 23 and $26^{\circ} \mathrm{C}$ produced the largest individuals. A $1^{\circ} \mathrm{C}$ change in environmental temperature produced a 1 to $15.5 \%$ difference in $B^{*}$ and 0.1 to $16.2 \%$ in $t^{*}$, which resulted in a 0.7 to $62.6 \%$ difference in body mass at the end of the simulation. Simulation at $13^{\circ} \mathrm{C}$ suggested that exponential growth would always be sustained in the first $100 \mathrm{~d}$.

\section{Model sensitivity}

Results from the sensitivity analyses performed with either $\pm 1 \%$ or $\pm 5 \%$ parameter changes were similar

Table 3. Octopus ocellatus and O. pallidus. Comparison of observed (obs.) with simulated (sim.) threshold body mass $B^{*}$ and transition age $t^{*}$. nt: no threshold

\begin{tabular}{|lccccc|}
\hline Species & $\begin{array}{c}\text { Temp. } \\
\left({ }^{\circ} \mathrm{C}\right)\end{array}$ & $\begin{array}{c}B^{*} \text { obs. } \pm 95 \% \\
\text { CI }(\mathrm{g})\end{array}$ & $\begin{array}{c}B^{*} \text { sim. } \\
(\mathrm{g})\end{array}$ & $\begin{array}{c}t^{*} \text { obs. } \pm 95 \% \\
\text { CI }(\mathrm{d})\end{array}$ & $\begin{array}{c}t^{*} \text { sim. } \\
(\mathrm{d})\end{array}$ \\
\hline O. ocellatus & 20.0 & $2.5 \pm 3.5$ & 5.3 & $43 \pm 27$ & 56.6 \\
& 25.0 & $2.3 \pm 1.6$ & 5.6 & $37 \pm 12$ & 52.4 \\
O. pallidus & 14.7 & $\mathrm{nt}$ & $\mathrm{nt}$ & $\mathrm{nt}$ & $\mathrm{nt}$ \\
& 16.9 & $\mathrm{nt}$ & $\mathrm{nt}$ & $\mathrm{nt}$ & $\mathrm{nt}$ \\
& & & & &
\end{tabular}

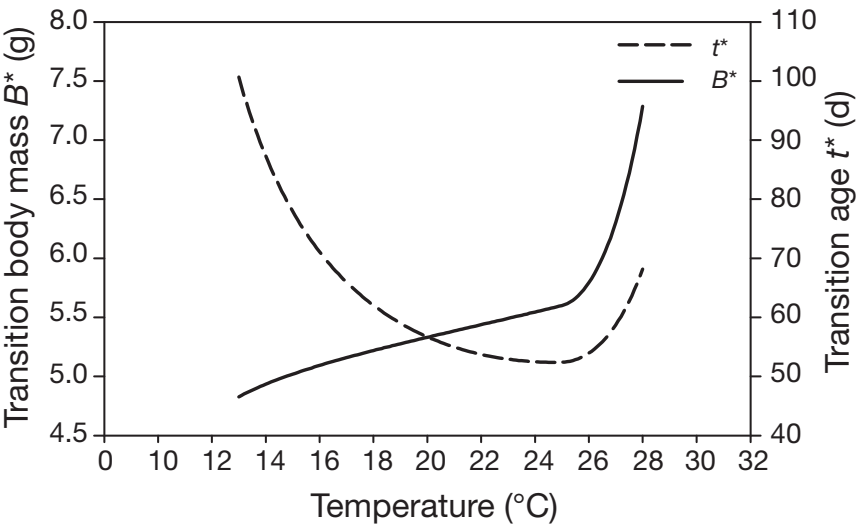

Fig. 5. Octopus ocellatus. Model threshold body mass $B^{*}$ and transition age $t^{*}$ as a function of environmental temperature $T$

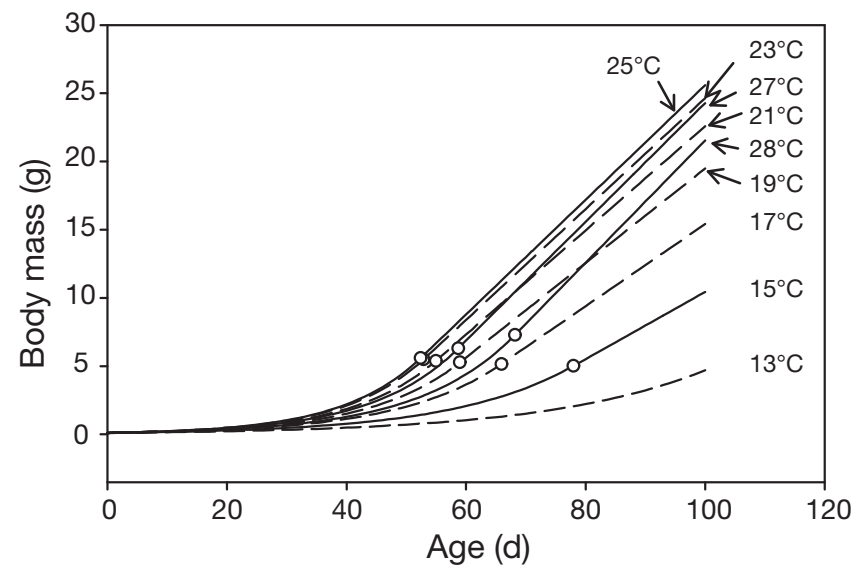

Fig. 6. Octopus ocellatus. Projected growth trajectories at selected environmental temperatures. (O): transition point $\left(t^{*}, B^{*}\right)$ for each individual

and hence for conciseness only the sensitivity analyses for a $1 \%$ increase are presented (Fig. 7).

The threshold body mass $B^{*}$ was most sensitive to increases imposed on metabolic rate parameters, in particular to changes in $b_{2}$ and $a_{2}$. The corresponding transition age $t^{*}$ exhibited a similar sensitivity profile. Temperature had the most effect on the sensitivity of $B^{*}$ to changes in the feeding parameter $T_{\text {fopt }}$ and growth parameter $T_{\mathrm{opt}}$. The sensitivity of $B^{*}$ to changes in metabolic parameters (and most feeding parameters) also increased with temperature, and was more pronounced at temperatures in the upper thermal range of the species. The sensitivity profile of transition age $t^{*}$ was similar to that of $B^{*}$ but was less influenced by temperature. 

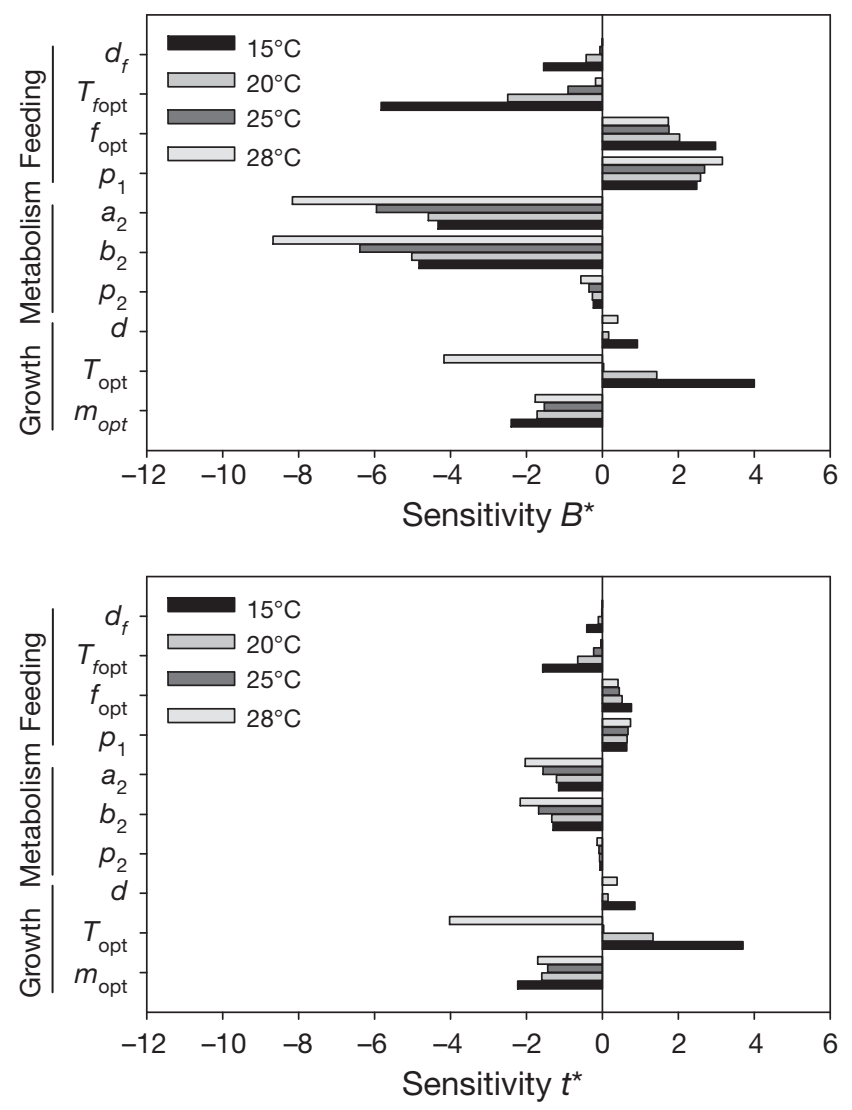

Fig. 7. Octopus ocellatus. Sensitivity to small perturbations in feeding, metabolism and growth rate parameters of (a) $B^{*}$ and (b) $t^{*}$ at $15,20,25$ and $28^{\circ} \mathrm{C}$. Elasticity was measured as the proportional change in $B^{*}$ (body mass threshold size) or $t^{*}$ (age at threshold size) resulting from a $1 \%$ increase in each parameter value

\section{DISCUSSION}

The energy balance paradigm reflected appropriately the conditions experienced by the animals and the growth pattern of both species, providing realistic estimations of the transition mass $B^{*}$ and transition age $t^{*}$ when 2-phase growth was detected experimentally. Results reinforce the hypothesis advanced by Forsythe (1993) that changes in environmental temperature as small as $1^{\circ} \mathrm{C}$ can have significant effect on cephalopod growth. A $1{ }^{\circ} \mathrm{C}$ increase in temperature in the model implied up to $15.5 \%$ change in the threshold body mass for Octopus ocellatus and considerably altered the growth trajectory of individuals.

The model suggests that the influence of temperature on threshold body mass $B^{*}$, and hence on the shape of individual growth curves, would be mostly driven by metabolism. Sensitivity analyses indicate metabolic rate is the most influential component of the model and will generally more acutely influence threshold body mass rather than threshold age, as reported for Sepia apama with the basic energy balance model (Grist \& Jackson 2004). More significantly, our analysis suggests that elevated temperature would increase the sensitivity of $B^{*}$ to changes in metabolic rate, which would have important ramifications on the structure of cephalopod populations in the coming decades. The predicted increase in seawater temperature combined with a reduction in seawater $\mathrm{pH}$, due to increasing $\mathrm{CO}_{2}$ levels in the oceans, will decrease the ability of cephalopods to bind oxygen for transport (Seibel \& Fabry 2003), therefore altering metabolic rate at the individual level. This would impact on the body mass at transition out of exponential growth, possibly affecting size at maturity, and is likely to substantially alter the population dynamics of most cephalopod species.

The reversal in the decreasing trend of $t^{*}$ observed in model projections at higher temperatures is connected to the optimal temperature for growth $T_{\mathrm{opt}}$. As temperature increases beyond that point, more energy becomes available from food while overall energy expenditure starts to decrease due to a decline in growth rate, hence delaying both the threshold time and body mass, at least until the optimal temperature for feeding $T_{f \text { opt }}$ is reached. The accurate estimation of $T_{\text {opt }}$ and $T_{\text {fopt }}$ is therefore crucial for these type of energetic models, but these data are sparse for octopus.

Currently, the lack of a complete range of data on feeding, metabolism and growth for cephalopod species is an impediment, and models such as the one presented here require drawing parameters from a wide range of species. The estimated transition point being just outside the $95 \% \mathrm{CI}$ at $25^{\circ} \mathrm{C}$ for Octopus ocellatus reflects these unavoidable approximations, and there is a need for concerted efforts to conduct the full range of observations on some species well suited to studies in captivity and representative of major fished species. There is also a need to establish whether temperature affects the metabolic rate and feeding rate exponents $p_{1}$ and $p_{2}$ for more species than just $O$. vulgaris (Katsanevakis et al. 2005). These exponents are considered temperature-independent in our analysis, but one or both of these parameters could vary with temperature with implications for size or age at transition out of exponential growth.

Energetic information on wild cephalopods is notoriously difficult to obtain. Average growth rate (Pecl 2004, Leporati et al. 2008) and aspects of metabolism (O'Dor et al. 1994, Webber et al. 2000, O'Dor 2002, Aitken et al. 2005) have successfully been estimated for a few species, but feeding data remains largely inaccessible. Carefully conducted laboratory studies with animals fed ad libitum and subject to minimal human interaction, as was the case for Octopus ocel- 
latus in the present study, are thought to be representative of feeding and growth rates of wild animals (Wells \& Clarke 1996), and remain the only option to fully parameterise energetics models for wild cephalopods. Field studies may never elucidate whether or not cephalopods demonstrate a 2-phase growth pattern in the wild. Growth curves that adequately represent the behaviour of a population mean can very poorly describe the pattern followed by any individual in that population (Alford \& Jackson 1993). Furthermore, while statolith (Jackson 1990) and stylet increment analyses (Doubleday et al. 2006, Leporati et al. 2008) provide insights into individual growth rate integrated over the life span, the lack of a relationship between increment width and daily growth rate (Jackson \& Moltschaniwskyj 2001) renders the detection of a change in growth difficult and the re-construction of individual growth curves impossible (Arkhipkin 2005). The present study suggests that a transition out of exponential growth is not a compulsory phase, and it may occur late, as seen for O. ocellatus at lower temperatures, or not at all, as seen for O. pallidus.

The model presented in the present paper is the first to include both body size and temperaturedependence in the overall energy budget of cephalopods and is adaptable to both squid and cuttlefish species. The incorporation of periodic variation in temperature to simulate seasonal water temperature would allow the inclusion of the 'Forsythe effect' (Forsythe 1993, 2004) and provide a better representation of the individual growth trajectories that are followed in natural populations. Individual variability could also be incorporated as stochastic variations in initial hatching size, which is known to significantly influence growth trajectory during the exponential phase (Pecl et al. 2004, Leporati et al. 2007). Such a model would permit a more in-depth exploration of population dynamics in natural cephalopod populations with great potential for improving fishery management by predicting population structure under prospective food and temperature scenarios. On a wider scale, this type of analyses could be used to predict how climate change might affect key cephalopod species. The negative impact of increasing $\mathrm{pH}$, linked to ocean warming, could be incorporated in the metabolism term of the energy balance equation, enabling predictions about population abundance and structure under different climate change scenarios. Moreover, these types of models have the capacity to predict optimum conditions for potentially competitive species and could be a powerful tool for understanding both the evolution of species and for predicting how climate change might affect species distribution.
Acknowledgements. We are grateful to S. Tracey, S. Foster and J. Clapcott for their advice on various aspects of this project. Experiments on Octopus pallidus complied with current Tasmanian and Australian laws and were approved by the Animal Ethics Committee of the University of Tasmania under project no. A0008385. Experiments on O. ocellatus conformed to relevant local animal welfare laws, guidelines and policies.

\section{LITERATURE CITED}

Aguado Giménez F, García García B (2002) Growth and food intake models in Octopus vulgaris Cuvier (1797): influence of body weight, temperature, sex and diet. Aquacult Int 10:361-377

Aitken JP, O'Dor RK, Jackson GD (2005) The secret life of the giant Australian cuttlefish Sepia apama (Cephalopoda): behaviour and energetics in nature revealed through radio acoustic positioning and telemetry (RAPT). J Exp Mar Biol Ecol 320:77-91

Alford RA, Jackson GD (1993) Do cephalopods and larvae of other taxa grow asymptotically? Am Nat 141:717-728

> André J, Pecl GT, Semmens JM, Grist EPM (2008) Early lifehistory processes in benthic octopus: relationships between temperature, feeding, food conversion, and growth in juvenile Octopus pallidus. J Exp Mar Biol Ecol 354: 81-92

Arkhipkin AI (2005) Statoliths as 'black boxes' (life recorders) in squid. Mar Freshw Res 56:573-583

Arkhipkin AI, Roa-Ureta R (2005) Identification of ontogenetic growth models for squid. Mar Freshw Res 56: 371-386

Barbeau MA, Caswell H (1999) A matrix model for short-term dynamics of seeded populations of sea scallops. Ecol Appl 9:266-287

Bartsch J (2002) Modelling the temperature mediation of growth in larval fish. Fish Oceanogr 11:310-314

Boyle PR, Knobloch D (1984) Male reproductive maturity in the octopus, Eledone cirrhosa (Cephalopoda: Octopoda). J Mar Biol Assoc UK 64:573-579

Boyle P, Rodhouse PG (2005) Cephalopods ecology and fisheries. Blackwell Science, Oxford

Calow P (1987) Fact and theory-an overview. In: Boyle PR (ed) Cephalopod life cycles, Vol 2. Academic Press, London, p 351-366

Caswell H (2001) Matrix population models: construction, analysis and interpretation. Sinauer Associates, Sunderland, MA

Clarke MR (1996) The role of cephalopods in the world's oceans: an introduction. Philos Trans R Soc Lond B Biol Sci 351:979-983

Cortez T, Castro BG, Guerra A (1995) Reproduction and condition of female Octopus mimus (Mollusca: Cephalopoda). Mar Biol 123:505-510

Crowley R (1999) Hydrochemistry operations manual. Report no. 236. CSIRO, Hobart

> Daly HI, Peck LS (2000) Energy balance and cold adaptation in the octopus Pareledone charcoti. J Exp Mar Biol Ecol 245:197-214

Domain F, Jouffre D, Caverivière A (2000) Growth of Octopus vulgaris from tagging in Senegalese waters. J Mar Biol Assoc UK 80:699-705

> Doubleday ZA, Semmens JM, Pecl GT, Jackson GD (2006) Assessing the validity of stylets as ageing tools in Octopus pallidus. J Exp Mar Biol Ecol 338:35-42

> Elliott JM, Davison W (1975) Energy equivalents of oxygen consumption in animal energetics. Oecologia 19:195-201 
FAO (2005) Global production statistics 1950-2005. FAO, Rome. Available at: www.fao.org/fishery/statistics/globalproduction (accessed Nov 15, 2007)

Forsythe JW (1993) A working hypothesis of how seasonal temperature change may impact the field growth of young cephalopods. In: Okutani T, O'Dor RK, Kubodera T (eds) Recent advances in fisheries biology. Tokai University Press, Tokyo, p 133-143

Forsythe JW (2004) Accounting for the effect of temperature on squid growth in nature: from hypothesis to practice. Mar Freshw Res 55:331-339

Forsythe JW, Hanlon RT (1988) Effect of temperature on laboratory growth, reproduction and life span of Octopus bimaculoides. Mar Biol 98:369-379

Forsythe JW, Van Heukelem WF (1987) Growth. In: Boyle PR (ed) Cephalopod life cycles, Vol 2. Academic Press, London, p 135-156

Gillooly JF, Brown JH, West GB, Savage VM, Charnov EL (2001) Effects of size and temperature on metabolic rate. Science 293:2248-2251

Grist EPM, Jackson GD (2004) Energy balance as a determinant of two-phase growth in cephalopods. Mar Freshw Res 55:395-401

Hatfield EMC, Hanlon RT, Forsythe JW, Grist EPM (2001) Laboratory testing of a growth hypothesis for juvenile squid Loligo pealeii (Cephalopoda: Loliginidae). Can J Fish Aquat Sci 58:845-857

Jackson GD (1990) Age and growth of the tropical nearshore Loliginid squid Sepioteuthis lessoniana determined from statolith growth-ring analysis. Fish Bull 88:113-118

> Jackson GD, Moltschaniwskyj NA (2001) The influence of ration level on growth and statolith increment width of the tropical squid Sepioteuthis lessoniana (Cephalopoda: Loliginidae): an experimental approach. Mar Biol 138: 819-825

Jackson GD, O'Dor RK (2001) Time, space and the ecophysiology of squid growth, life in the fast lane. Vie Milieu 51: 205-215

> Joll LM (1977) Growth and food intake of Octopus tetricus (Mollusca: Cephalopoda) in aquaria. Aust J Mar Freshw Res 28:45-56

Katsanevakis S, Stephanopoulou S, Miliou H, Moraitou-Apostolopoulou M, Verriopoulos G (2005) Oxygen consumption and ammonia excretion of Octopus vulgaris (Cephalopoda) in relation to body mass and temperature. Mar Biol 146:725-732

Kleiber M (1932) Body size and animal metabolism. Hilgardia 6:315-353

Kleiber M (1947) Body size and metabolic rate. Physiol Rev 27:511-541

> Lauzon-Guay JS, Barbeau MA, Watmough J, Hamilton DJ (2006) Model for growth and survival of mussels Mytilus edulis reared in Prince Edward Island, Canada. Mar Ecol Prog Ser 323:171-183

Leporati SC, Pecl GT, Semmens JM (2007) Cephalopod hatchling growth: the effects of initial size and seasonal temperatures. Mar Biol 151:1375-1383

Leporati SC, Semmens JM, Pecl GT (2008) Determining the age and growth of wild octopus using stylet increment analysis. Mar Ecol Prog Ser 367:213-222

Lindstrom MJ, Bates DM (1990) Nonlinear mixed effects models for repeated measures data. Biometrics 46:673-687

Major GA, Dal Pont G, Klye J, Newell B (1972) Laboratory techniques in marine chemistry, a manual. Report no. 51. CSIRO, Cronulla

Mangold K (1983) Food, feeding and growth in cephalopods. Mem Natl Mus Victoria 44:81-93
Mangold K (1987) Reproduction. In: Boyle PR (ed) Cephalopod life cycles, Vol 2. Academic Press, London, p 157-200

Mangold K, von Boletzky S (1973) New data on reproductive biology and growth of Octopus vulgaris. Mar Biol 19:7-12

McKinney RA, Glatt SM, Williams SR (2004) Allometric length-weight relationships for benthic prey of aquatic wildlife in coastal marine habitats. Wildl Biol 10:241-249

O'Dor RK (2002) Telemetered cephalopod energetics: swimming, soaring and blimping. Integr Comp Biol 42: 1065-1070

O'Dor RK, Wells MJ (1987) Energy and nutrient flow. In: Boyle PR (ed) Cephalopod life cycles, Vol 2. Academic Press, London, p 109-133

O'Dor RK, Hoar JA, Webber DM, Carey FG, Tanaka S, Martins HR, Porteiro FM (1994) Squid (Loligo forbesi) performance and metabolic rates in nature. Mar Freshw Behav Physiol 25:163-177

O'Dor RK, Aitken JP, Jackson GD (2005) Energy balance growth models: applications to cephalopods. Phuket Mar Biol Cent Res Bull 66:329-336

Pecl GT (2004) The in situ relationships between season of hatching, growth and condition in the southern calamary, Sepioteuthis australis. Mar Freshw Res 55:429-438

Pecl GT, Steer MA, Hodgson KE (2004) The role of hatchling size in generating the intrinsic size-at-age variability of cephalopods: extending the Forsythe hypothesis. Mar Freshw Res 55:387-394

Perez JAA, Haimovici M (1991) Sexual maturation and reproductive cycle of Eledone massyae, Voss 1964 (Cephalopoda: Octopodidae) in southern Brazil. Bull Mar Sci 49: 270-279

Perez MC, Lopez DA, Aguila K, Gonzalez ML (2006) Feeding and growth in captivity of the octopus Enteroctopus megalocyathus Gould, 1852. Aquac Res 37:550-555

Petza D, Katsanevakis S, Verriopoulos G (2006) Experimental evaluation of the energy balance in Octopus vulgaris, fed ad libitum on a high-lipid diet. Mar Biol 148:827-832

Prosser CL (1973) Comparative animal physiology. WB Saunders, Philadelphia, PA

Ricker WE (1979) Growth rates and models. In: Hoar WS, Randall DJ, Brett JR (eds) Fish physiol, Vol VIII. Bioenergetics and growth. Academic Press, New York, p 677-743

Segawa S, Nomoto A (2002) Laboratory growth, feeding, oxygen consumption and ammonia excretion of Octopus ocellatus. Bull Mar Sci 71:801-813

Seibel BA, Fabry VJ (2003) Marine biotic response to elevated carbon dioxide. In: Hannah L, Lovejoy T (eds) Climate change and biodiversity: synergistic impacts, Vol 4. Center for Applied Biodiversity Science, Conservation International, Washington, DC, p 59-67

Semmens JM, Pecl GT, Villanueva R, Jouffre D, Sobrino I, Wood JB, Rigby PR (2004) Understanding octopus growth: patterns, variability and physiology. Mar Freshw Res 55: 367-377

Van Heukelem WF (1973) Growth and life-span of Octopus cyanea (Mollusca:Cephalopoda). J Zool 169:299-315

> von Bertalanffy L (1957) Quantitative laws in metabolism and growth. Q Rev Biol 32:217-231

> Webber DM, Aitken JP, O'Dor RK (2000) Costs of locomotion and vertic dynamics of cephalopods and fish. Physiol Biochem Zool 73:651-662

- Wells MJ, Clarke A (1996) Energetics: the costs of living and reproducing for an individual cephalopod. Philos Trans R Soc Lond B Biol Sci 351:1083-1104

Wells MJ, O'Dor RK, Mangold K, Wells J (1983) Feeding and metabolic rate in octopus. Mar Behav Physiol 9:305-317

West GB, Brown JH, Enquist BJ (1997) A general model for 
the origin of allometric scaling laws in biology. Science 276:122-126

Winberg GC (1956) Rate of metabolism and food requirements of fishes. Belorussian State University, Minsk (translated from Russian by Fish Res Board Can Transl Serv no. 194, 1960)

Zeuthen E (1953) Oxygen uptake as related to body size in organisms. Q Rev Biol 28:1-12

Appendix 1. Oxygen consumption of juvenile pale octopus Octopus pallidus

\section{AIM}

The dependence of metabolic rate $M$ on body mass $B$ is characterised by an allometric scaling law of the form $M=$ $q_{2} B^{p_{2}}$. The purpose of the experiment was to estimate the species' metabolic rate exponent $p_{2}$.

\section{METHODS}

We reared pale octopus Octopus pallidus hatchlings from eggs in $250 \mathrm{l}$ stock tanks under fluorescent lighting replicating natural daylight $(06: 00$ to $18: 00 \mathrm{~h}$ light, 18:00 to 06:00 h dark), and measured the oxygen consumption of 2 juveniles on 3 occasions at age 94, 134 and $148 \mathrm{~d}$. All measurements were taken between 10:00 and 15:00 h while the animals were in post-digestive conditions (at least $12 \mathrm{~h}$ after feeding). Animals were placed in individual $600 \mathrm{ml}$ clear plastic respirometers and a gentle flow of oxygenated water was passed through the respirometer for a period of $1 \mathrm{~h}$ in order to acclimatise the octopuses before measurements were taken (Fig. A1a). Care was taken to ensure that no air bubbles were trapped in the chambers. The water used in the respirometers was the same as that from the rearing tanks and was filtered $(10 \mu \mathrm{m})$ before entering the chambers (Fig. A1b). Respirometers were immersed in a controlled-temperature water bath to maintain a constant temperature of $18^{\circ} \mathrm{C}$ for the duration of the experiment. Five respirometers were set up for each temperature treatment (4 with octopus and 1 blank). Respirometers were attributed randomly to octopuses to avoid any bias. After the acclimatisation period, respirometers were sealed by closing both taps. To ensure complete homogeneity of the sample, water was slowly mixed with a clear stirrer for $20 \mathrm{~s}$ before each sampling. This manipulation did not seem to disturb the octopus, which did not display any colour changes, rapid movements or noticeable increase in ventilation.

Water was sampled through the outflow with a $20 \mathrm{ml}$ syringe, ensuring that no air was drawn into the syringe. The outflow tap was opened and the plunger slowly pressed to expel water samples. The first $5 \mathrm{ml}$ of water expelled was discarded as this corresponded to still water sitting in the outflow tube. The duration of the experiment was $180 \mathrm{~min}$ for the measurements at $94 \mathrm{~d}$ and $120 \mathrm{~min}$ for the measurements at 134 and $148 \mathrm{~d}$. Water samples for oxygen analysis and temperature measurements were removed hourly. Oxygen concentration was determined using a modified Winkler titration method (Major et al. 1972, Crowley 1999). In the modified method, volume was scaled down to $20 \mathrm{ml}$ and manganese sulphate solution and potassium iodide/sodium hydroxide solution were micropipetted directly into the syringe. Duplicate titrations were carried out for each sample (two $10 \mathrm{ml}$ titrations). All volumes of water extracted during the experiment were recorded precisely to correct the subsequent oxygen concentrations for volume. Oxygen consumption rate was calculated in $\mu \mathrm{O}_{2} \mathrm{~g}$ octopus ${ }^{-1} \mathrm{~h}^{-1}$ and converted to $\mathrm{kJ} \mathrm{d}^{-1}$.

\section{RESULTS AND CONCLUSION}

Oxygen consumption rate in $\mathrm{kJ} \mathrm{d}^{-1}$ was expressed as $M=$ $0.0546 B^{0.8774}$ (Fig. A2) and we hence estimated $p_{2}$ at 0.88 for Octopus pallidus. (a)

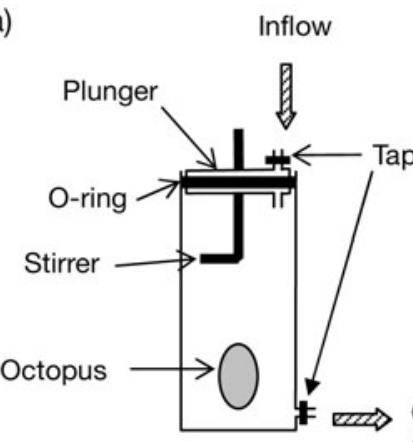

(b)

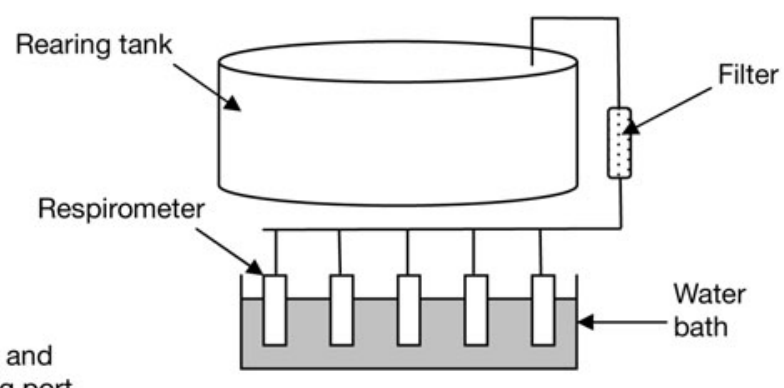

Outflow and

Fig. A1. (a) Respirometer design and (b) experimental setup for the oxygen consumption experiment 
Appendix 1 (continued)

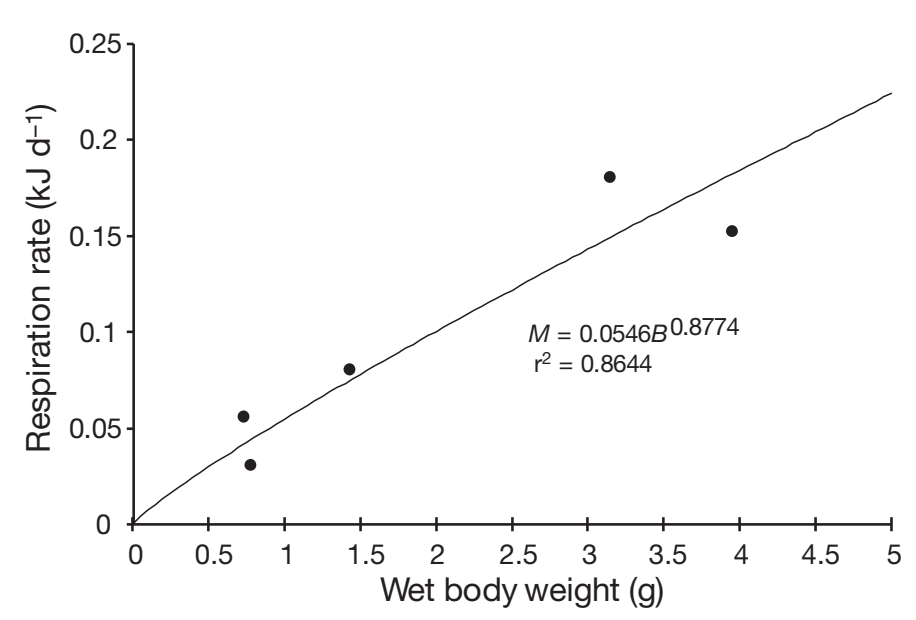

Fig. A2. Octopus pallidus. Oxygen consumption $M$ as a function of body weight $B$ for juvenile octopus at $18^{\circ} \mathrm{C}$

Editorial responsibility: Yves Cherel, Villiers-en-Bois, France
Submitted: April 11, 2008; Accepted: September 12, 2008 Proofs received from author(s): December 11, 2008 